\title{
Novel Anode Catalyst for Direct Methanol Fuel Cells
}

\author{
S. Basri, ${ }^{1}$ S. K. Kamarudin, ${ }^{1,2}$ W. R. W. Daud, ${ }^{1}$ Z. Yaakob, ${ }^{2}$ and A. A. H. Kadhum ${ }^{2}$ \\ ${ }^{1}$ Fuel Cell Institute, Universiti Kebangsaan Malaysia (UKM), 43600 Bangi, Selangor, Malaysia \\ ${ }^{2}$ Department of Chemical and Process Engineering, Universiti Kebangsaan Malaysia (UKM), 43600 Bangi, Selangor, Malaysia
}

Correspondence should be addressed to S. K. Kamarudin; ctie@eng.ukm.my

Received 8 January 2014; Revised 21 March 2014; Accepted 21 March 2014; Published 27 April 2014

Academic Editor: Tebello Nyokong

Copyright (C) 2014 S. Basri et al. This is an open access article distributed under the Creative Commons Attribution License, which permits unrestricted use, distribution, and reproduction in any medium, provided the original work is properly cited.

\begin{abstract}
$\mathrm{PtRu}$ catalyst is a promising anodic catalyst for direct methanol fuel cells (DMFCs) but the slow reaction kinetics reduce the performance of DMFCs. Therefore, this study attempts to improve the performance of PtRu catalysts by adding nickel (Ni) and iron (Fe). Multiwalled carbon nanotubes (MWCNTs) are used to increase the active area of the catalyst and to improve the catalyst performance. Electrochemical analysis techniques, such as energy dispersive X-ray spectrometry (EDX), X-ray diffraction (XRD), field emission scanning electron microscopy (FESEM), and X-ray photoelectron spectroscopy (XPS), are used to characterize the kinetic parameters of the hybrid catalyst. Cyclic voltammetry (CV) is used to investigate the effects of adding Fe and Ni to the catalyst on the reaction kinetics. Additionally, chronoamperometry (CA) tests were conducted to study the long-term performance of the catalyst for catalyzing the methanol oxidation reaction (MOR). The binding energies of the reactants and products are compared to determine the kinetics and potential surface energy for methanol oxidation. The FESEM analysis results indicate that well-dispersed nanoscale $(2-5 \mathrm{~nm})$ PtRu particles are formed on the MWCNTs. Finally, PtRuFeNi/MWCNT improves the reaction kinetics of anode catalysts for DMFCs and obtains a mass current of $31 \mathrm{~A} \mathrm{~g}^{-1}$ catalyst.
\end{abstract}

\section{Introduction}

Most fuel cell catalytic electrodes, including DMFC anodes, are made of either platinum or platinum-based materials [1]. However, many problems that prevent the commercialization of DMFCs remain unsolved, such as poor performance, catalyst instability, methanol crossover, and thermal and water management [2-4]. Thus, this study focused on the poor methanol oxidation kinetics, which is partially attributed to catalyst poisoning $[5,6]$ of the anode by reaction intermediates such as CO [7]. During methanol oxidation, strongly adsorbed CO blocks Pt sites required for the oxidative adsorption of methanol. The enthalpy of adsorption is tuned by varying the alloy composition (compositional tuning) or electrode potential (Stark tuning). Such variations affect the interactions between $\mathrm{CO}$ molecular orbitals (MOs) and metal substrate bands. Changes in the electronic structure of mixed-metal catalysts are monitored by polarizationmodulated infrared reflection adsorption spectroscopy (PMIRAS) of adsorbed CO $[8,9]$. Therefore, to improve DMFC efficiency, anode electrocatalysts that enhance methanol oxidation activity and minimize CO poisoning must be considered.

The high reactivity of Pt makes it a suitable anode electrocatalyst for DMFCs. However, pure Pt is readily poisoned by carbon monoxide $(\mathrm{CO})$, the main intermediate species formed by an indirect reaction during methanol oxidation. This indirect reaction occurs because less energy is required to form $\mathrm{CO}$ than $\mathrm{CO}_{2}$. Therefore, to avoid the formation of $\mathrm{CO}$ on Pt electrodes, binary or hybrid alloys of $\mathrm{Pt}$, such as PtRu, PtSn [10], Pt-M [11], PtMO [12], PtPbMnO [13], and PtCo $[14,15]$, are generally employed as electrocatalytic materials on DMFC anodes. In DMFCs, bimetallic PtRu is the most widely used catalytic material because of its high electrocatalytic activity towards methanol oxidation at the anode. $\mathrm{Ru}$ improved the electronic properties of $\mathrm{Pt}$ to prevent the adoption of $\mathrm{CO}$ by decreasing the oxidation overpotential of the anode [16]. However, slow reaction kineticsis a significant limitation that reduces the performance and power output of DMFCs. 
Thus, two major improvements are essential in catalyst layer design: the incorporation of $\mathrm{Pt}[17]$ or Pt-group $[18,19]$ nanoparticles and the impregnation or colloidal mixing of a high surface area carbon support with an ionomer. Several $\mathrm{PtRu}$-metal groups have been considered as potential anode catalysts for DMFCs, including rhodium ( $\mathrm{Rh})$, iron ( $\mathrm{Fe})$, nickel (Ni), and cobalt (Co). Of these metal groups, Park et al. [20] studied the effect of adding nickel and rhodium. In their study, the PtRuRhNi catalyst obtained a high oxidation current of $100 \mathrm{~mA} \mathrm{~cm}^{-1}$ at high operating temperatures $\left(70^{\circ} \mathrm{C}\right)$. Jeon et al. [21] studied several catalyst combinations, including $\mathrm{Pt}_{45} \mathrm{Ru}_{45} \mathrm{Fe}_{10} / \mathrm{C}, \mathrm{Pt}_{45} \mathrm{Ru}_{45} \mathrm{Co}_{10} / \mathrm{C}$, and $\mathrm{Pt}_{45} \mathrm{Ru}_{45} \mathrm{Ni}_{10} / \mathrm{C}$. Among these catalysts, the $\mathrm{Pt}_{45} \mathrm{Ru}_{45} \mathrm{Fe}_{10} / \mathrm{C}$ catalyst exhibited the highest mass activity of $2.6 \mathrm{Ag} \mathrm{g}^{-1}$ catalyst, whereas the mass activities of the $\mathrm{Pt}_{45} \mathrm{Ru}_{45} \mathrm{Co}_{10} / \mathrm{C}$ and $\mathrm{Pt}_{45} \mathrm{Ru}_{45} \mathrm{Ni}_{10} / \mathrm{C}$ catalysts were 2.2 and $2.5 \mathrm{~A} \mathrm{~g}^{-1}$ catalyst, respectively. With respect to specific activity, the catalysts exhibited much higher activities of 110, 120, and $150 \mathrm{~mA} \mathrm{~m}^{-2}$ for the Fe-, Co-, and $\mathrm{Ni}$-incorporated catalysts, respectively, than $88 \mathrm{~mA} \mathrm{~m}^{-2}$ of a commercial PtRu/C catalyst. Later, Jeon et al. [22] improved the $\mathrm{PtRuFe} / \mathrm{C}$ catalyst and obtained mass and specific activities of $5.67 \mathrm{~A} \mathrm{~g}^{-1}$ catalyst and $177 \mathrm{~mA} \mathrm{~m}^{-2}$, respectively.

Wang et al. [26] also demonstrated via electrochemical impedance spectroscopy (EIS) that the performance of the $\mathrm{PtRuNi} / \mathrm{C}$ catalyst for methanol electrooxidation was much better than that of the $\mathrm{PtRu} / \mathrm{C}$ catalyst. This result was supported by Wang et al. [27], Ribeiro et al. [16], and Liu et al. [25] through their experimental studies on PtRu/C, in which they obtained mass activities of $3.7,5.1$, and $9.0 \mathrm{~A} \mathrm{~g}^{-1}$ catalyst, respectively. Jiang et al. [28] also demonstrated that a carbon-supported $\mathrm{PtNi} / \mathrm{C}$ electrocatalyst showed enhanced mass activity for the methanol oxidation reaction compared to a $\mathrm{Pt} / \mathrm{C}$ catalyst. In addition, the deposition of Pt nanoparticles on highly ordered carbon nanotubes (CNTs) has been reported as one of the reasons for the significantly increased methanol oxidation activity. In fact, the development of carbon catalyst support materials, such as carbon porous materials (CPM), carbon nanotubes (CNT), and activated carbon, and the addition of noble metals to catalysts are gaining considerable attention as two methods to improve methanol oxidation and DMFC efficiency [1].

Considering the great performance of $\mathrm{Fe}$ and $\mathrm{Ni}$ compared to other metals from previous studies, this study proposed a novel catalyst adopting $\mathrm{Fe}$ and $\mathrm{Ni}$ incorporated with PtRu using MWCNTs as a catalyst support. This study characterized the PtRuFeNi/MWCNT using electrochemical techniques such as energy dispersive X-ray (EDX) spectrometry, $\mathrm{X}$-ray diffraction (XRD), X-ray photoelectron spectroscopy (XPS), and field emission scanning electron microscopy (FESEM). This study also investigated the effects of adding $\mathrm{Fe}$ and $\mathrm{Ni}$ atoms on the reaction kinetics using cyclic voltammetry $(\mathrm{CV})$. This study also employed chronoamperometry tests to study the stability of the catalysts for the methanol oxidation reaction (MOR). Finally, this study determined and compared the mass activity and the specific activity of the proposed novel catalyst with other types of catalysts.

\section{Experimental}

2.1. Preparation of a Nanocatalyst. Industrial-grade MWCNTs were purified by refluxing in $60 \% \mathrm{HNO}_{3}$ at $90^{\circ} \mathrm{C}$ for $2 \mathrm{~h}$. The mixture was diluted with water, filtered, washed with excess deionized (DI) water, and dried overnight at $50^{\circ} \mathrm{C}$ in a vacuum oven. After purification, surface oxidation of MWCNTs was achieved by refluxing MWCNTs in $4 \mathrm{M}$ $\mathrm{H}_{2} \mathrm{SO}_{4}$ and $4 \mathrm{M} \mathrm{HNO}_{3}$ at $90^{\circ} \mathrm{C}$ for $5 \mathrm{~h}$. Finally, the treated MWCNTs were diluted with water, filtered, washed with excess DI water, and dried overnight at $50^{\circ} \mathrm{C}$ in a vacuum oven. PtRu nanoparticles were synthesized using $\mathrm{NaBH}_{4}$ as a reducing agent and deposited on MWCNTs along with $\mathrm{H}_{2} \mathrm{PtCl}_{6}(0.0065 \mathrm{mM})$ and $\mathrm{RuCl}_{3} \cdot 6 \mathrm{H}_{2} \mathrm{O}$ (0.0065 mM) precursors in tetrahydrofuran (THF) [29]. After the reduction reaction, the mixture was stirred for $2 \mathrm{~h}$ at room temperature. Finally, the mixture was filtered, washed with excess DI water, and dried in a vacuum oven at $70^{\circ} \mathrm{C}$ for $30 \mathrm{~min}$. Using the above procedure, PtRuFe/MWCNTs, PtRuNi/MWCNTs, and PtRuFeNi/MWCNTs (20 wt\%) were also synthesized. For comparison, another method in which the stirring process was replaced with ultrasonic homogenization was also performed. The results from the two methods were compared in terms of particle size, distribution, and morphology using TEM.

2.2. Physical Characterization. The catalyst morphology was observed via TEM at $100 \mathrm{kV}$ for samples diluted in the methanol solution. The sample was coated with gold before determining the elements contained in the sample using EDX, which was attached to the FESEM (SUPRA $55 \mathrm{VP})$. Under vacuum conditions of $1 \times 10^{9}$ torr, AESXPS (Kratos Axis DLD) is used for chemical state analysis of atoms in the ten layers from the surface. One gram of sample was used for approximately $1-3 \mathrm{~h}$ of operation. XRD (D8 ADVANCE) was used for the physical characterization of the samples placed on a glass slip. The allowable scanning angle is between $5^{\circ}$ and $90^{\circ}$ degrees $2 \theta$.

2.3. Electrochemical Analysis. A conventional three-electrode cell was constructed. A glassy carbon (GC) electrode with an area of $0.125 \mathrm{~cm}^{2}$ was used as the working electrode, a Pt wire was used as the counter electrode, and a saturated calomel electrode (SCE) was used as the reference electrode. The catalyst ink was prepared by first dispersing $7.2 \mathrm{mg}$ of PtRu/MWCNTs and PtRu/MWCNTs (S) in $2.5 \mathrm{~mL}$ of ethanol with ultrasonication. Then, $0.5 \mathrm{~mL}$ of $0.1 \mathrm{wt} \%$ Nafion was added and dispersed with ultrasonication for $30 \mathrm{~min}$. After sonication, $10 \mathrm{~mL}$ of the solution was added to the GC electrode. The electrode was dried at $70^{\circ} \mathrm{C}$ to yield a PtRu loading of $0.048 \mathrm{mg} \mathrm{cm}^{-2}$. CV experiments were performed in a solution containing $0.5 \mathrm{M} \mathrm{H}_{2} \mathrm{SO}_{4}$ and $1 \mathrm{M}$ $\mathrm{CH}_{3} \mathrm{OH}$ at a scan rate of $50 \mathrm{mV} \mathrm{s}^{-1}$ [29] for in situ conditions. Ten consecutive runs were performed to obtain stable results. 
TABLE 1: Particle sizes calculated from the XRD results.

\begin{tabular}{lcccc}
\hline Catalyst sample & FCC & 2 Theta $\left(^{\circ}\right)$ & Full-width at half-maximum, FWHM $\left(^{\circ}\right)$ & Particle size-XRD $($ nm $)$ \\
\hline PtRu/MWCNT & $(111)$ & 39.814 & 1.089 & 11.97 \\
PtRuFeNi/MWCNT & $(111)$ & 40.193 & 1.982 & 4.646 \\
PtRuFe/MWCNT & $(110)$ & 21.597 & 0.274 & 32.02 \\
\hline
\end{tabular}

TABLE 2: Specification of platinum $4 \mathrm{f}$ peaks [23].

\begin{tabular}{lccc}
\hline Peak & Binding energy $(\mathrm{eV})$ & Atomic mass (\%) & Component \\
\hline Pt 1 & 71.9 & 33.39 & $\mathrm{Pt}$ \\
Pt 2 & 73.0 & 21.26 & $\mathrm{PtNi}$ \\
Pt 3 & 75.0 & 25.24 & $\mathrm{Pt}$ \\
Pt 4 & 76.2 & 20.1 & $\mathrm{Pt}\left(\mathrm{C}_{32} \mathrm{H}_{16} \mathrm{~N}_{8}\right)$ \\
\hline
\end{tabular}

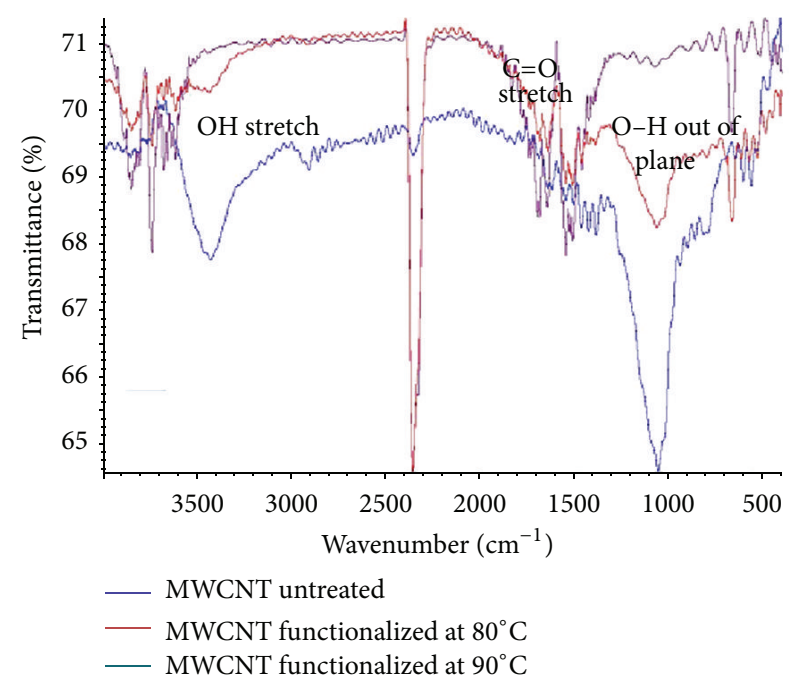

FIGURE 1: FT-IR analyses for pure MWCNTs before treatment and after treatment at $80^{\circ} \mathrm{C}$ and $90^{\circ} \mathrm{C}$.

\section{Results and Discussion}

Initially, untreated MWCNTs contained only $\mathrm{C}-\mathrm{C}$ bonds and no $-\mathrm{OH}$ bonds, as shown in Figure 1. Because $\mathrm{C}-\mathrm{C}$ bonds are difficult to break, an oxidation process was used to facilitate the formation of $-\mathrm{OH}$ molecules on the MWCNTs. During catalyst synthesis, platinum and ruthenium from the $\mathrm{H}_{2} \mathrm{PtCl}_{6}$ and $\mathrm{RuCl}_{3} \cdot 6 \mathrm{H}_{2} \mathrm{O}$ precursors take advantage of $-\mathrm{OH}$ bonds to provide better adsorption, which is called impregnation. The formation of $-\mathrm{OH}$ bonds on the MWCNTs was confirmed by FT-IR analysis of surface functional groups. The FT-IR results for MWCNTs refluxed at $90^{\circ} \mathrm{C}$ show the presence of $-\mathrm{OH}$ bonds, in contrast to the MWCNTs refluxed at $80^{\circ} \mathrm{C}$. Therefore, temperature is a significant parameter for $-\mathrm{OH}$ bond formation. FT-IR bands correlating to $-\mathrm{OH}$ functional groups were observed at $3400-3600 \mathrm{~cm}^{-1}$, $1400 \mathrm{~cm}^{-1}$, and $1000 \mathrm{~cm}^{-1}$. MWCNTs treated at temperatures lower than $80^{\circ} \mathrm{C}$ did not exhibit obvious $-\mathrm{OH}$ stretching or in-plane bending. In contrast, MWCNTs treated at $90^{\circ} \mathrm{C}$ exhibited transmittance at all wavenumbers consistent with -OH stretching and both in-plane and out-of-plane bending.
The water in the fuel cell is oxidized to a hydroxy radical via the following reaction: $\mathrm{H}_{2} \mathrm{O} \rightarrow \mathrm{OH}^{\bullet}+\mathrm{H}^{+}+\mathrm{e}^{-}$. The hydroxy radical then oxidizes carbon monoxide to produce carbon dioxide, which is released from the surface as a gas: $\mathrm{CO}+\mathrm{OH}^{\bullet} \rightarrow \mathrm{CO}_{2}+\mathrm{H}^{+}+$e. It was also found that $\mathrm{COOH}$ may occur in the wavenumber range from 3400 to $2400 \mathrm{~cm}^{-1}$, which is very broad and overlaps with C$\mathrm{H}$ and $\mathrm{O}-\mathrm{H}$ stretching. However, this study focuses on the existence of $\mathrm{OH}$ after the oxidation process to provide better adsorption.

Energy dispersive X-ray (EDX) spectrometry was used to quantify the atomic composition of the nanocatalysts. Figures 2(a) and 2(b) present the EDX results for nanocatalysts synthesized using the reduction method. From the graph, the atomic composition of the nanocatalysts was observed to be either $5 \%$ or $15 \%$ platinum. To increase the performance and reduce cost, nickel and iron were added to the nanocatalysts. Figure 3 presents the surface morphologies of PtRu/MWCNTs and PtRuFeNi/MWCNTs after synthesis, which indicates that they are well distributed.

The X-ray diffraction (XRD) results presented in Figure 4 indicate that all prepared metal catalysts presented a typical face-centered cubic (fcc) crystallographic structure. Compared to the PtRuFeNi/MWCNT catalyst, there was a slight shift in the X-ray diffraction peaks of the PtRu/MWCNT catalyst to higher Bragg angles. This shift indicates that bimetallic interactions or alloying occurred in the catalyst. The small peak observed at $40^{\circ}$ for the PtRuFe/MWCNT sample is attributed to $\mathrm{Pt}$ (111). The weak intensity and broad peak width indicate high metallic dispersion in the prepared sample.

The particle size was calculated using the Debye-Scherrer equation [23] with data from the XRD analysis as follows:

$$
\text { Particle Size }=\frac{k \propto}{B \cos \theta},
$$

where $k=0.98$ and $\alpha=0.154 \mathrm{~nm}$.

Table 1 shows the particle sizes determined from the XRD results using the full width at half-maximum (FWHM) parameter. The particle size of PtRu/MWCNTs was found to be $11.97 \mathrm{~nm}$.

The formation of the nanohybrid catalyst was characterized by XPS, as shown in Figure 5. The XPS spectra of 


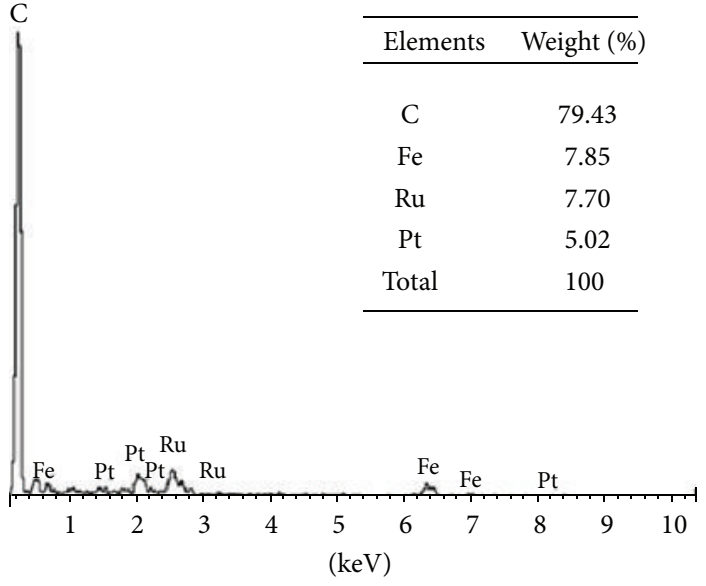

(a)

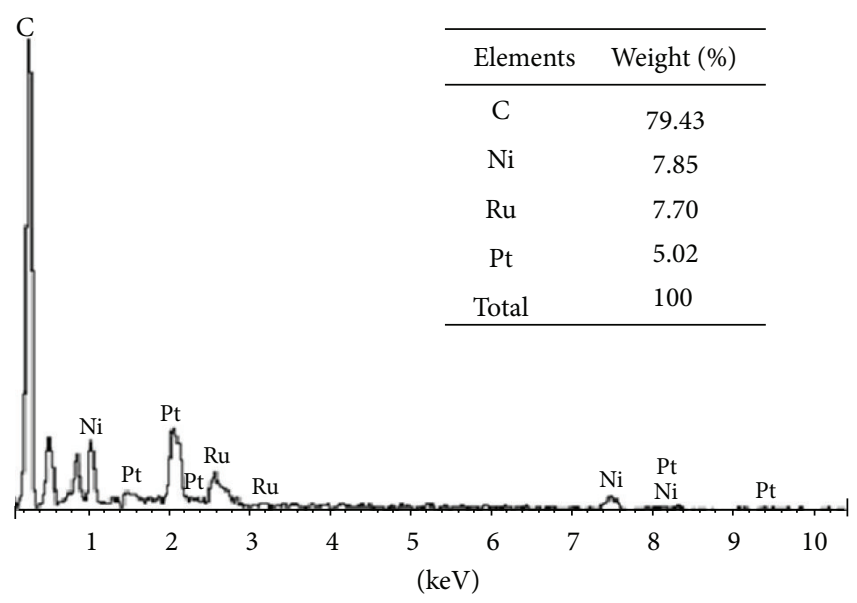

(b)

FIGURE 2: EDX results for MWCNT-based nanocatalyst with the addition of (a) iron and (b) nickel.

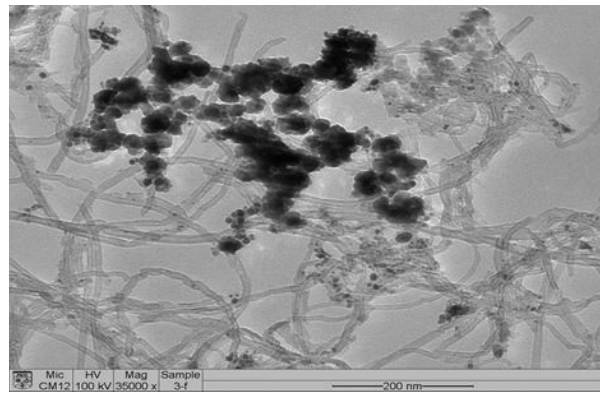

(a)

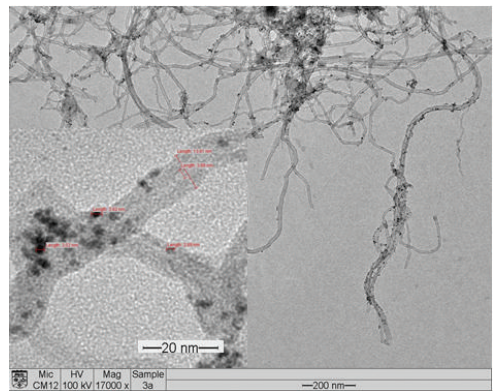

(b)

Figure 3: Morphologies of (a) PtRuFeNi/MWCNT and (b) PtRu/MWCNT.

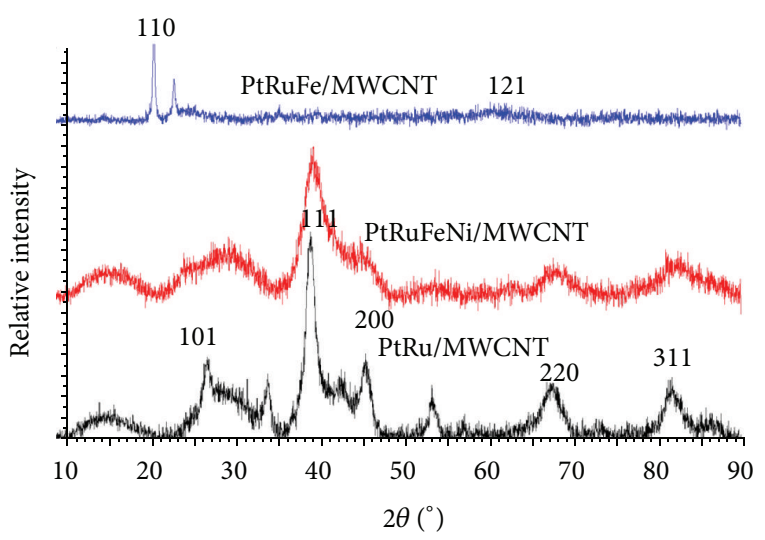

Figure 4: XRD patterns of PtRu/MWCNT, PtRuFeNi/MWCNT, and PtRuFe/MWCNT.

the $\mathrm{Co} / \mathrm{Fe} / \mathrm{Ni} / \mathrm{CNT}$ composite exhibited the Pt $4 \mathrm{f}$ binding energy double peak corresponding to $\mathrm{Pt} 1$ at $73 \mathrm{eV}$ and $\mathrm{Pt} 3$ at $75 \mathrm{eV}$. Several binding energies were used to determine the elemental composition of materials bonded to Pt. Table 2 lists Pt bonding components from [30].

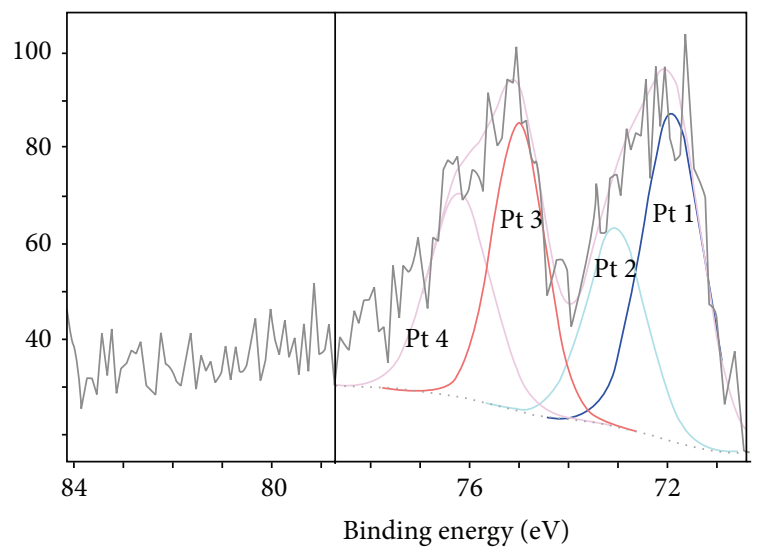

FIgURE 5: XPS analysis for Pt 4f.

Figure 6(a) shows the cyclic voltammograms for the Pt catalyst with a catalyst loading of $0.048 \mathrm{mg} \mathrm{cm}^{-2}$. A current density of $50 \mathrm{~mA} \mathrm{mg}^{-1}$, which increased with each consecutive $\mathrm{CV}$ run, was observed for the PtRuFeNi/MWCNT nanocatalyst with a Pt loading of $0.027 \mathrm{mg} \mathrm{cm}^{-2}$. The PtRuFe/MWCNT, PtRuNi/MWCNT, 


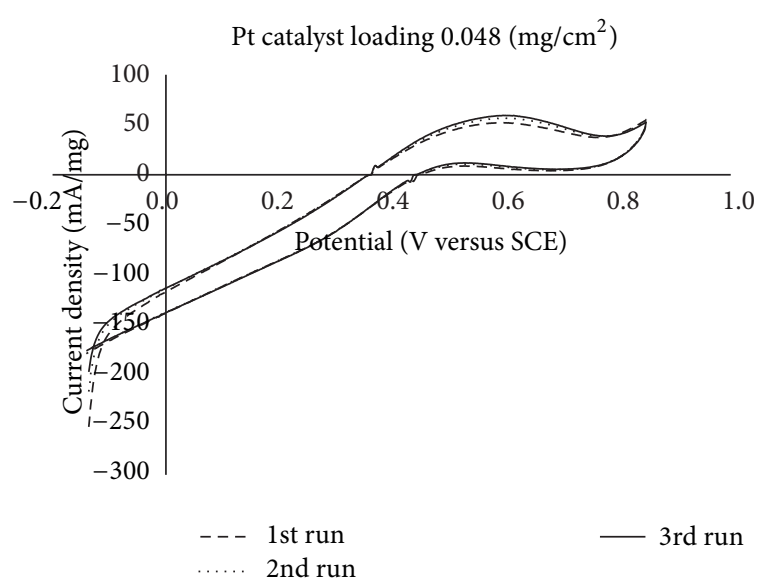

(a)

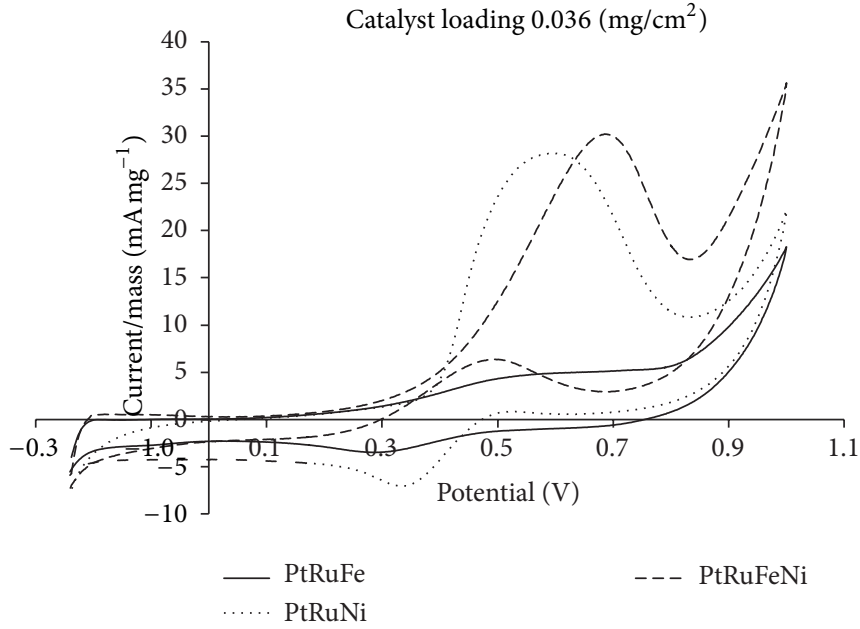

(b)

FIgURE 6: Cyclic voltammetry for MWCNT-based nanocatalyst.

TABLE 3: Summary of the cyclic voltammetry results.

\begin{tabular}{lccccc}
\hline Compound & $\begin{array}{c}\text { Catalyst loading } \\
\left(\mathrm{mg} \mathrm{cm}^{-2}\right)\end{array}$ & $\begin{array}{c}\text { Percent of Pt from } \\
20 \% \text { of catalyst }(\%)\end{array}$ & $\begin{array}{c}\text { Pt loading } \\
\left(\mathrm{mg} \mathrm{cm}^{-2}\right)\end{array}$ & $\begin{array}{c}\text { Current density } \\
\left(\mathrm{mA} \mathrm{mg}^{-1}\right)\end{array}$ & $\begin{array}{c}\text { Potential } \\
(\mathrm{V})\end{array}$ \\
\hline Pt/MWCNT & 0.048 & 100 & 0.048 & 50 & 0.60 \\
PtRuFe/MWCNT & 0.036 & 10 & 0.0036 & 0.027 & 28 \\
PtRuNi/MWCNT & 0.036 & 75 & 0.027 & 31 & 0.50 \\
PtRuNiFe/MWCNT & 0.036 & 75 & & & 0.70 \\
\hline
\end{tabular}

and PtRuFeNi/MWCNT nanocatalysts were also subjected to 10 consecutive cyclic voltammetry runs. As observed in Figure 6(b), the performance of the PtRuFeNi/MWCNT catalysts, in terms of current density, was high compared to the performances of the other materials. The performance of the PtRuFe/MWCNT catalysts was the lowest of the analyzed nanocatalysts because it contained only a small amount of $\mathrm{Pt}(5 \%)$, whereas the other materials contained $15 \% \mathrm{Pt}$. Comparing the performance of PtRuNi/MWCNTs to PtRuFeNi/MWCNTs, it was observed that the addition of $\mathrm{Fe}^{2+}$ ions increased the current density. Therefore, iron and nickel additives have the potential to increase catalyst performance in DMFCs and to reduce cost [21]. Figure 6(b) shows low current density values for all samples but high potential values when a catalyst loading of $0.036 \mathrm{mg} \mathrm{cm}^{-2}$ was used. This result is attributed to the large active area of the nanocatalyst at low catalyst loading values.

Table 3 summarizes the CV results of the nanocatalysts. From this table, it is clear that the current densities of $\mathrm{Pt} / \mathrm{MWCNT}$ and PtRuFeNi/MWCNTs are comparable, even though the PtRuNiFe/MWCNTs contained a smaller amount of Pt. This result demonstrates that PtRuFeNi/MWCNTs nanocatalysts could improve the performance and kinetics of the oxidation reaction and reduce the cost of catalysts used in the membrane electrode assembly (MEA) by $15 \%$. Similar studies used current density or mass activity as the parameter to assess the performance of DMFCs using different types of catalysts. Current density was used to
TABLE 4: Comparison of the current density with other studies.

\begin{tabular}{lcc}
\hline Study & Item & Current density $\left(\mathrm{mA} \mathrm{mg}^{-1}\right)$ \\
\hline This study & PtRuFeNi/MWCNT & 31 \\
Guo et al. [24] & $\mathrm{PtRu} / \mathrm{C}$ & 20 \\
Jeon et al. [21] & $\mathrm{Pt}_{45} \mathrm{Ru}_{45} \mathrm{Fe}_{10} / \mathrm{C}$ & 2.6 \\
Jeon et al. [22] & $\mathrm{PtRuFe} / \mathrm{MWCNT}^{\mathrm{M}}$ & 5.67 \\
Liu et al. [25] & PtRuNi/C & 9.0 \\
\hline
\end{tabular}

determine the methanol oxidation activity based on varying catalyst compositions in half-cell configurations. Table 4 compares the results obtained from this study with those from previous research. Finally, this study demonstrated that PtRuFeNi/MWCNTs achieved the highest current density, $31 \mathrm{~mA} \mathrm{mg}^{-1}$, compared to other types of reported catalysts, namely, PtRu/MWCNTs, PtRuFe/MWCNTs, and PtRuNi/MWCNTs.

Chronoamperometry tests were conducted to compare the long-term performance of the catalysts towards the MOR in a $0.5 \mathrm{M} \mathrm{H}_{2} \mathrm{SO}_{4}$ solution containing methanol for $5400 \mathrm{~s}$. Figure 7 shows the chronoamperometry curves for the PtRuFeNi/MWCNT, PtRuFe/MWCNT, and PtRuNi/MWCNT catalysts in $0.5 \mathrm{M} \mathrm{H}_{2} \mathrm{SO}_{4}+1 \mathrm{M} \mathrm{CH} \mathrm{CH}_{3} \mathrm{OH}$ at a constant potential of $0.4 \mathrm{~V}$. During the initial stage, the potentiostatic current decreased rapidly for both the PtRuFe and PtRuNi catalysts, perhaps due to the formation 


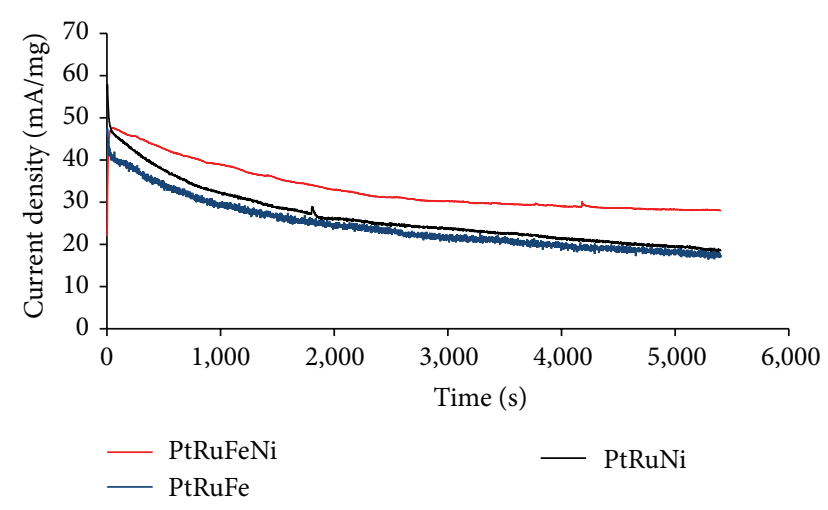

FIgURE 7: Chronoamperometry curves for (a) PtRuFeNi/MWCNT, PtRuFe/MWCNT, and PtRuNi/MWCNT in a $0.5 \mathrm{M} \mathrm{H}_{2} \mathrm{SO}_{4}+1 \mathrm{M}$ $\mathrm{CH}_{3} \mathrm{OH}$ solution.

of intermediate species, such as COads, $\mathrm{CH}_{3} \mathrm{OHads}$, and CHOads, during the methanol oxidation reaction. After a long duration of operation, although the current gradually decayed for all catalysts, PtRuFeNi/MWCNT maintained a slightly higher current than the other catalysts. The long time decay can be attributed to the adsorbed $\mathrm{SO}_{4}{ }^{2-}$ anion on the surface of the PtRu catalysts, which can restrict the methanol oxidation reaction [29].

In summary, CNTs coated with metal nanoparticles are gaining considerable interest for use as sensors, catalysts, and metal nanowires and for applications in nanoelectronics, such as in field-effect transistor (FET) devices. However, the attachment of metal nanoparticles to CNTs during synthesis causes distortions in the CNT geometry. In this study, MWCNTs were synthesized with $\mathrm{Pt}, \mathrm{Ru}, \mathrm{Fe}$, and $\mathrm{Ni}$ using the reducing agent $\mathrm{NaBH}_{4}$. During reduction, $-\mathrm{OH}$ bonds were broken and replaced with metallic molecules. Consistent with Hyun et al. [31], the $\mathrm{NaBH}_{4}$ concentration was found to affect the deposition and surface composition of the prepared PtRu particles [25]. For optimal methanol electrooxidation, the molar ratio of $\mathrm{NaBH}_{4}$ to metal ions was determined to be $5: 15$. During synthesis, the MWCNT structures became distorted. However, this result is typical and occurs because of changes in the atomic distance of $\mathrm{C}-\mathrm{C}$ bonds. This is a natural structure for CNTs. This result was confirmed by Raman spectrometry, as shown in Figure 8 . The Raman emission intensity increases with the fourth power of the frequency of the source, and Raman intensities are usually directly proportional to the concentration of the active species, as shown in Figure 8. The intensity or power of a normal Raman peak has a complex dependence on the polarizability of the molecule, the intensity of the source, and the concentration of the active group, such as an attached catalyst. The change in the polarizability of a molecule during vibration is related to how easily a molecule can be deformed. This is observed in Figure 8, where the Gband spectra are located at a higher wavelength $\left(1580 \mathrm{~cm}^{-1}\right)$ than D-band $\left(1300 \mathrm{~cm}^{-1}\right)$ in the Raman spectrum which indicates the formation of $\mathrm{PtRu} / \mathrm{CNT}$. This result is due to the surface chemistry that occurs during the oxidation and

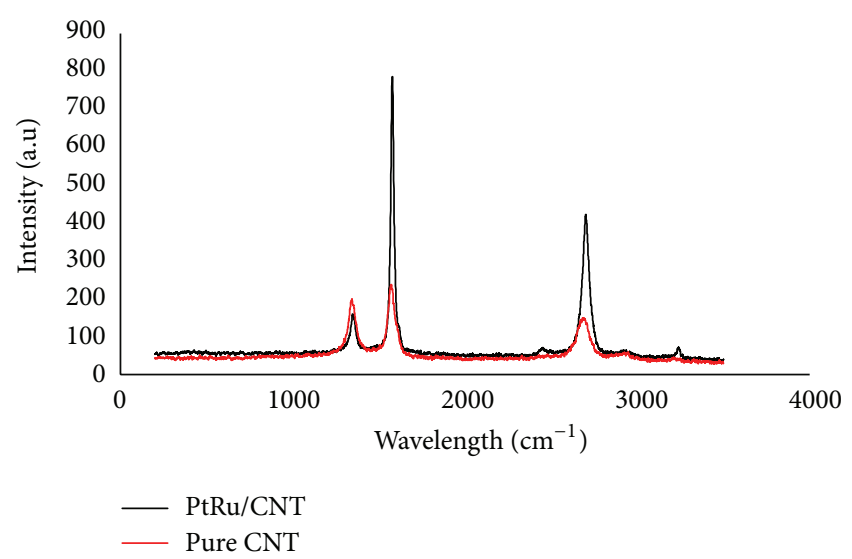

FIgURE 8: Raman spectra for PtRu/CNT and pure CNT.

synthesis process, which modifies the chemical composition of a surface by incorporating - $\mathrm{OH}$ onto a nanocatalyst metal.

Table 5 shows the reduction in cost for the anode catalyst presented in this study. The cost analysis was based on the amount of catalyst used for PtRu by Guo et al. [24]. It is observed that the cost of PtRuFeNi was reduced by approximately $20 \%$ based on the catalyst loading in comparison to PtRu and that it obtained a higher mass current density. The cost of the Fe, Ni catalyst and MWCNTs as a supported material did not significantly affect the total cost because they are very inexpensive compared to PTRu, as listed in Table 6. Finally, this study concluded that the PtRuFeNi catalyst introduced in this study can save up to $20 \%$ and achieves a higher mass current density than PtRu.

\section{Conclusions}

In this work, we performed two main studies: one study focused on improving the pretreatment of the catalyst support and the other focused on optimizing the synthesis of the catalyst. Based on the FT-IR results, $90^{\circ} \mathrm{C}$ was determined to be the optimal temperature for the pretreatment of the nanocatalyst supports. Four nanocatalysts with varying metal compositions were synthesized using a reduction process, namely, Pt/MWCNT (as a reference), PtRuFe/MWCNT, PtRuNi/MWCNT, and PtRuFeNi/MWCNT. The samples were subjected to physical and chemical analyses. Particle morphology and crystallinity were used to determine the particle size. All of the samples were nanoscale, approximately $2-30 \mathrm{~nm}$, and uniform in distribution. Catalyst performance was assessed using CV in units of current density; the performance of PtRuFeNi/MWCNTs was slightly higher compared with the performance of the other nanocatalysts, and the current density was similar to that of Pt/MWCNTs. The amount of platinum in the catalyst also affected the CV results. PtRuFe/MWCNTs had the lowest current density values because this material contained less $\mathrm{Pt}$ than PtRuFeNi/MWCNTs. The chronoamperometry test demonstrated that, although the current gradually decayed for all the catalysts, PtRuFeNi maintained a higher current and was more stable compared to PtRuNi and PtRuFe. This result 
TABLE 5: Cost reduction.

\begin{tabular}{|c|c|c|c|c|c|}
\hline Compound & Ref. & PtRu loading $\left(\mathrm{mg} \mathrm{cm}^{-2}\right)$ & $\begin{array}{c}\text { Fe/Ni loading } \\
\left(\mathrm{mg} \mathrm{cm}^{-2}\right)\end{array}$ & Current density $\left(\mathrm{mA} \mathrm{mg}^{-1}\right)$ & Cost reduction (\%) \\
\hline $\mathrm{PtRu}$ & {$[24]$} & 0.048 & - & 20 & - \\
\hline PtRuNiFe & This study & 0.027 & $\begin{array}{l}0.0033 \mathrm{Ni} \\
0.0033 \mathrm{Fe}\end{array}$ & 31 & 21 \\
\hline
\end{tabular}

TABLE 6: List of current price.

\begin{tabular}{lc}
\hline Compound & Cost per mg, USD \\
\hline PtRu & 0.054 \\
Fe & $4.5 \times 10^{-6}$ \\
$\mathrm{Ni}$ & $7.7 \times 10^{-5}$ \\
MWCNT & 0.0012 \\
\hline
\end{tabular}

is evidence that the stability and kinetic parameters of the DMFC nanocatalyst were improved by the addition of both nickel and iron. Finally, the cost reduction analysis revealed that PtRuFeNi is capable of reducing the cost of anode catalysts for DMFCs by up to $20 \%$ compared with PtRu.

\section{Conflict of Interests}

The authors declare that there is no conflict of interests regarding the publication of this paper.

\section{Acknowledgments}

The authors acknowledge the financial support provided by Universiti Kebangsaan Malaysia through Arus Perdana Research University Grant, Grant no. UKM-DIP-2012-04, and Malaysia Toray Science Foundation UKM-MTSF-012010.

\section{References}

[1] S. Basri, S. K. Kamarudin, W. R. W. Daud, and Z. Yaakub, "Nanocatalyst for direct methanol fuel cell (DMFC)," International Journal of Hydrogen Energy, vol. 35, no. 15, pp. 7957-7970, 2010.

[2] S. H. Seo and C. S. Lee, "A study on the overall efficiency of direct methanol fuel cell by methanol crossover current," Applied Energy, vol. 87, no. 8, pp. 2597-2604, 2010.

[3] M. M. Ahmad, S. K. Kamarudin, W. R. W. Daud, and Z. Yaakub, "High power passive $\mu \mathrm{DMFC}$ with low catalyst loading for small power generation," Energy Conversion and Management, vol. 51, no. 4, pp. 821-825, 2010.

[4] H. S. Thiam, W. R. W. Daud, S. K. Kamarudin et al., "Overview on nanostructured membrane in fuel cell applications," International Journal of Hydrogen Energy, vol. 36, no. 4, pp. 3187-3205, 2011.

[5] T. Page, R. Johnson, J. Hormes, S. Noding, and B. Rambabu, "Study of methanol electro-oxidation reactions in carbon membrane electrodes and structural properties of Pt alloy electrocatalysts by EXAFS," Journal of Electroanalytical Chemistry, vol. 485, no. 1, pp. 34-41, 2000.
[6] N. A. Karim and S. K. Kamarudin, "An overview on nonplatinum cathode catalysts for direct methanol fuel cell," Applied Energy, vol. 103, pp. 212-220, 2013.

[7] T. S. Mozer and F. B. Passos, "Selective CO oxidation on $\mathrm{Cu}$ promoted $\mathrm{Pt} / \mathrm{Al} 2 \mathrm{O} 3$ and $\mathrm{Pt} / \mathrm{Nb} 2 \mathrm{O} 5$ catalysts," International Journal of Hydrogen Energy, vol. 36, no. 21, pp. 13369-13378, 2011.

[8] R. Liu, H. Iddir, Q. Fan et al., "Attraction-repulsion mechanism for carbon monoxide adsorption on platinum and platinumruthenium alloys," Journal of Physical Chemistry B, vol. 104, pp. 3518-3531, 2000

[9] Y. Tong, S. K. Hee, P. K. Babu, P. Waszczuk, A. Wieckowski, and E. Oldfield, "An NMR investigation of CO tolerance in a $\mathrm{Pt} / \mathrm{Ru}$ fuel cell catalyst," Journal of the American Chemical Society, vol. 124, no. 3, pp. 468-473, 2002.

[10] A. Sandoval-González, E. Borja-Arco, J. Escalante, O. JiménezSandoval, and S. A. Gamboa, "Methanol oxidation reaction on $\mathrm{PtSnO} 2$ obtained by microwave-assisted chemical reduction," International Journal of Hydrogen Energy, vol. 37, no. 2, pp. 17521759, 2012.

[11] V. Baglio, A. Stassi, A. di Blasi, C. D’Urso, V. Antonucci, and A. $\mathrm{S}$. Aricò, "Investigation of bimetallic $\mathrm{Pt}-\mathrm{M} / \mathrm{C}$ as DMFC cathode catalysts," Electrochimica Acta, vol. 53, no. 3, pp. 1360-1364, 2007.

[12] M. V. Martínez-Huerta, N. Tsiouvaras, M. A. Peña, J. L. G. Fierro, J. L. Rodríguez, and E. Pastor, "Electrochemical activation of nanostructured carbon-supported PtRuMo electrocatalyst for methanol oxidation," Electrochimica Acta, vol. 55, no. 26, pp. 7634-7642, 2010.

[13] Y. Huang, J. Cai, and Y. Guo, "Roles of $\mathrm{Pb}$ and $\mathrm{MnOx}$ in $\mathrm{PtPb} / \mathrm{MnOx}-\mathrm{CNTs}$ catalyst for methanol electro-oxidation," International Journal of Hydrogen Energy, vol. 37, no. 2, pp. 12631271, 2012.

[14] C. Xu, J. Hou, X. Pang, X. Li, M. Zhu, and B. Tang, "Nanoporous PtCo and PtNi alloy ribbons for methanol electrooxidation," International Journal of Hydrogen Energy, vol. 37, pp. 1048910498, 2012.

[15] B. P. Vinayan, R. I. Jafri, R. Nagar, N. Rajalakshmi, K. Sethupathi, and S. Ramaprabhu, "Catalytic activity of platinumcobalt alloy nanoparticles decorated functionalized multiwalled carbon nanotubes for oxygen reduction reaction in PEMFC," International Journal of Hydrogen Energy, vol. 37, no. 1, pp. 412421, 2012.

[16] V. A. Ribeiro, O. V. Correa, A. O. Neto, M. Linardi, and E. V. Spinacé, "Preparation of $\mathrm{PtRuNi} / \mathrm{C}$ electrocatalysts by an alcohol-reduction process for electro-oxidation of methanol," Applied Catalysis A: General, vol. 372, no. 2, pp. 162-166, 2010.

[17] J. W. Guo, T. S. Zhao, J. Prabhuram, and C. W. Wong, "Preparation and the physical/electrochemical properties of a $\mathrm{Pt} / \mathrm{C}$ nanocatalyst stabilized by citric acid for polymer electrolyte fuel cells," Electrochimica Acta, vol. 50, no. 10, pp. 1973-1983, 2005.

[18] M. Okada, Y. Konta, and N. Nakagawa, "Carbon nano-fiber interlayer that provides high catalyst utilization in direct 
methanol fuel cell," Journal of Power Sources, vol. 185, no. 2, pp. 711-716, 2008.

[19] A. L. Zhu, M. Y. Teo, and S. A. Kulinich, "A novel improvement on nano-deposition of $\mathrm{Ru}$ on $\mathrm{Pt}$ for fuel cell applications," Applied Catalysis A: General, vol. 352, no. 1-2, pp. 17-26, 2009.

[20] K.-W. Park, J.-H. Choi, S.-A. Lee, C. Pak, H. Chang, and Y.E. Sung, "PtRuRhNi nanoparticle electrocatalyst for methanol electrooxidation in direct methanol fuel cell," Journal of Catalysis, vol. 224, no. 2, pp. 236-242, 2004.

[21] M. K. Jeon, J. Y. Won, K. R. Lee, and S. I. Woo, "Highly active PtRuFe/C catalyst for methanol electro-oxidation," Electrochemistry Communications, vol. 9, no. 9, pp. 2163-2166, 2007.

[22] M. K. Jeon, K. R. Lee, H. Daimon, A. Nakahara, and S. I. Woo, "Pt45Ru45M10/C (M = Fe, Co, and Ni) catalysts for methanol electro-oxidation," Catalysis Today, vol. 132, no. 1-4, pp. 123-126, 2008.

[23] B. D. Cullity and S. R. Stock, Elements of X-Ray Diffraction, Prentice Hall, New York, NY, USA, 3rd edition, 2001.

[24] J. W. Guo, T. S. Zhao, J. Prabhuram, R. Chen, and C. W. Wong, "Preparation and characterization of a PtRu/C nanocatalyst for direct methanol fuel cells," Electrochimica Acta, vol. 51, no. 4, pp. 754-763, 2005.

[25] J. Liu, J. Cao, Q. Huang, X. Li, Z. Zou, and H. Yang, "Methanol oxidation on carbon-supported $\mathrm{Pt}-\mathrm{Ru}-\mathrm{Ni}$ ternary nanoparticle electrocatalysts," Journal of Power Sources, vol. 175, no. 1, pp. 159-165, 2008.

[26] Z.-B. Wang, G.-P. Yin, Y.-Y. Shao, B.-Q. Yang, P.-F. Shi, and P.-X. Feng, "Electrochemical impedance studies on carbon supported PtRuNi and PtRu anode catalysts in acid medium for direct methanol fuel cell," Journal of Power Sources, vol. 165, no. 1, pp. 9-15, 2007.

[27] W. Wang, R. Wang, H. Wang et al., "An advantageous method for methanol oxidation: design and fabrication of a nanoporous PtRuNi trimetallic electrocatalyst," Journal of Power Sources, vol. 196, no. 22, pp. 9346-9351, 2011.

[28] Q. Jiang, L. Jiang, S. Wang, J. Qi, and G. Sun, "A highly active $\mathrm{PtNi} / \mathrm{C}$ electrocatalyst for methanol electro-oxidation in alkaline media," Catalysis Communications, vol. 12, no. 1, pp. 6770, 2010.

[29] J. Prabhuram, T. S. Zhao, Z. X. Liang, and R. Chen, "A simple method for the synthesis of PtRu nanoparticles on the multi-walled carbon nanotube for the anode of a DMFC," Electrochimica Acta, vol. 52, no. 7, pp. 2649-2656, 2007.

[30] 2012, http://srdata.nist.gov/xps.

[31] M.-S. Hyun, S.-K. Kim, B. Lee, D. Peck, Y. Shul, and D. Jung, "Effect of $\mathrm{NaBH} 4$ concentration on the characteristics of PtRu/C catalyst for the anode of DMFC prepared by the impregnation method," Catalysis Today, vol. 132, no. 1-4, pp. 138-145, 2008. 

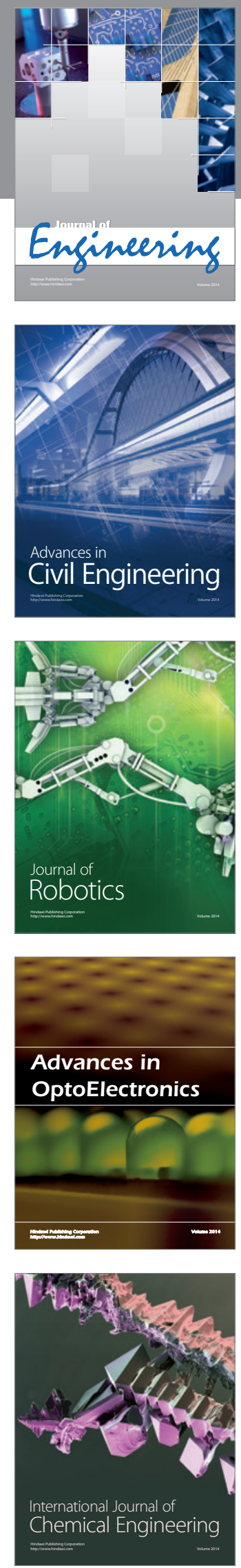

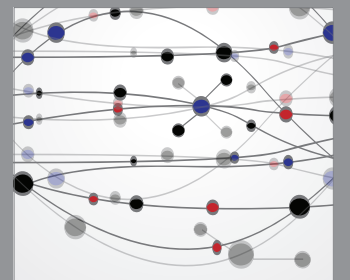

The Scientific World Journal
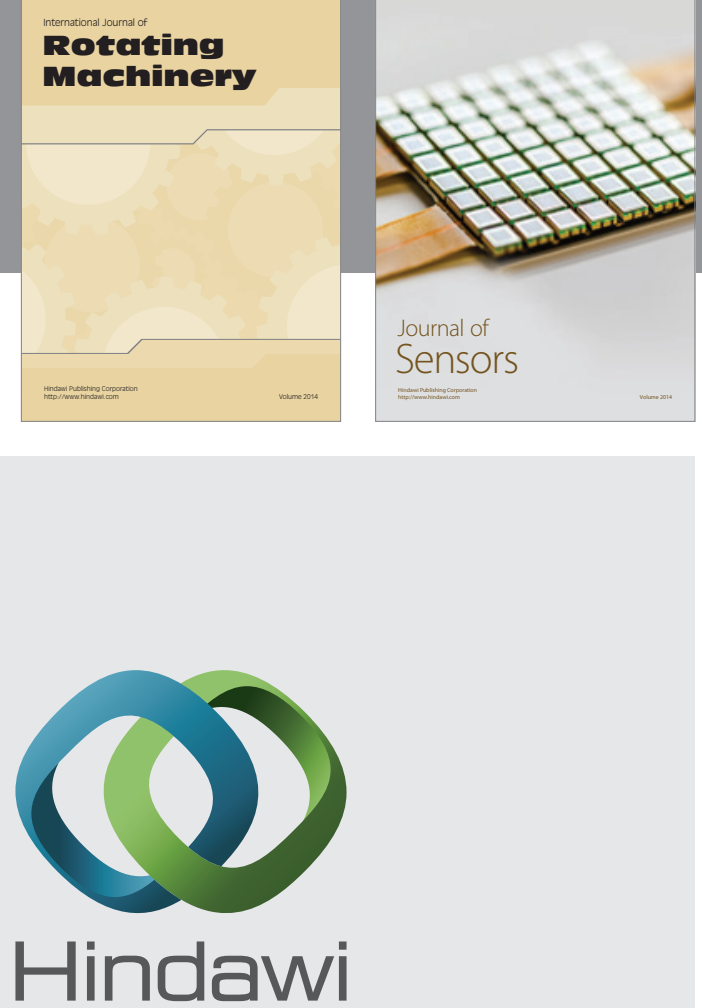

Submit your manuscripts at http://www.hindawi.com
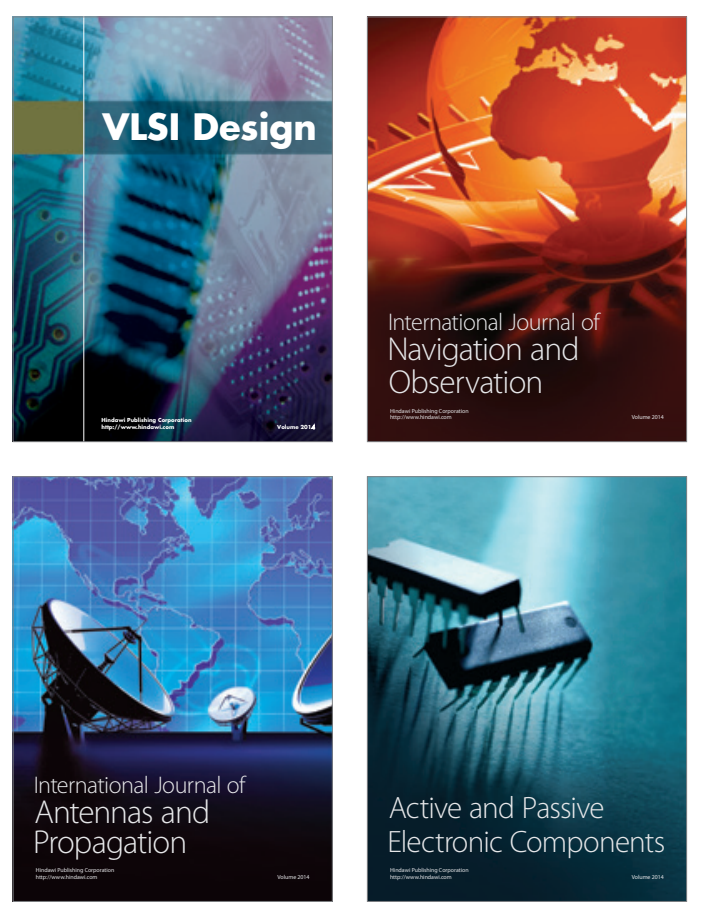
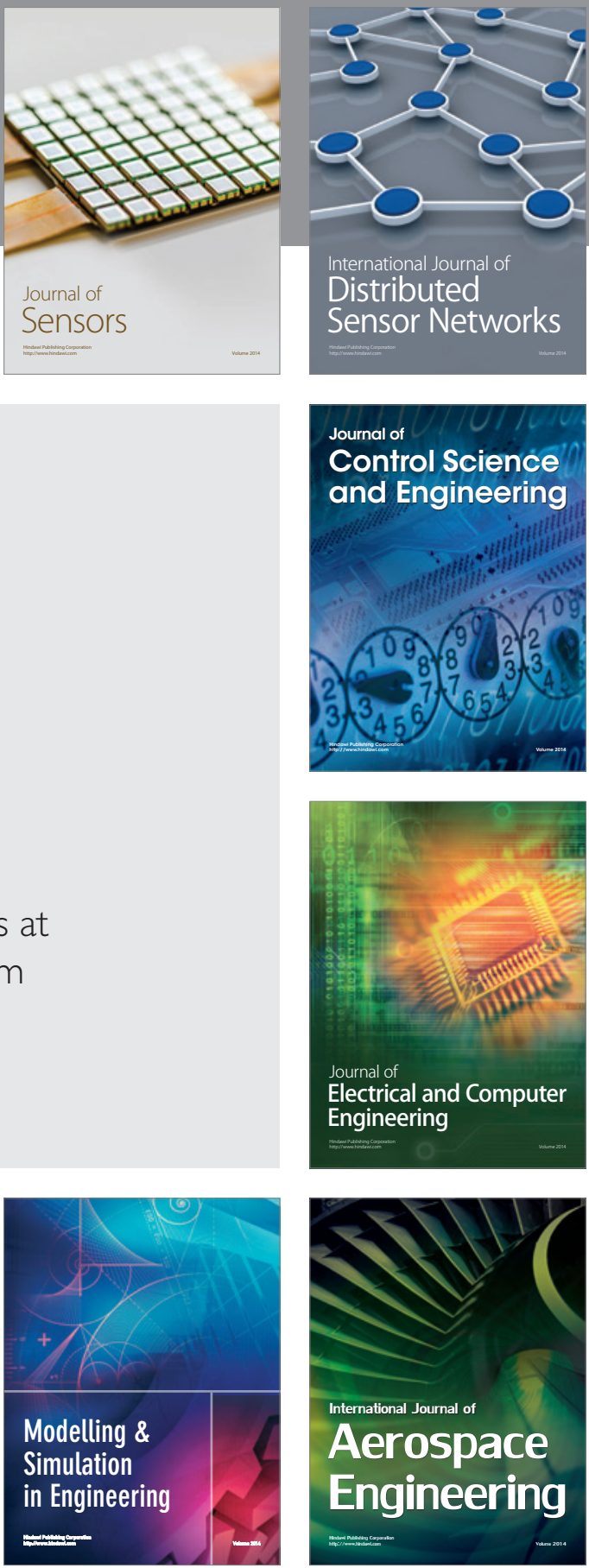

Journal of

Control Science

and Engineering
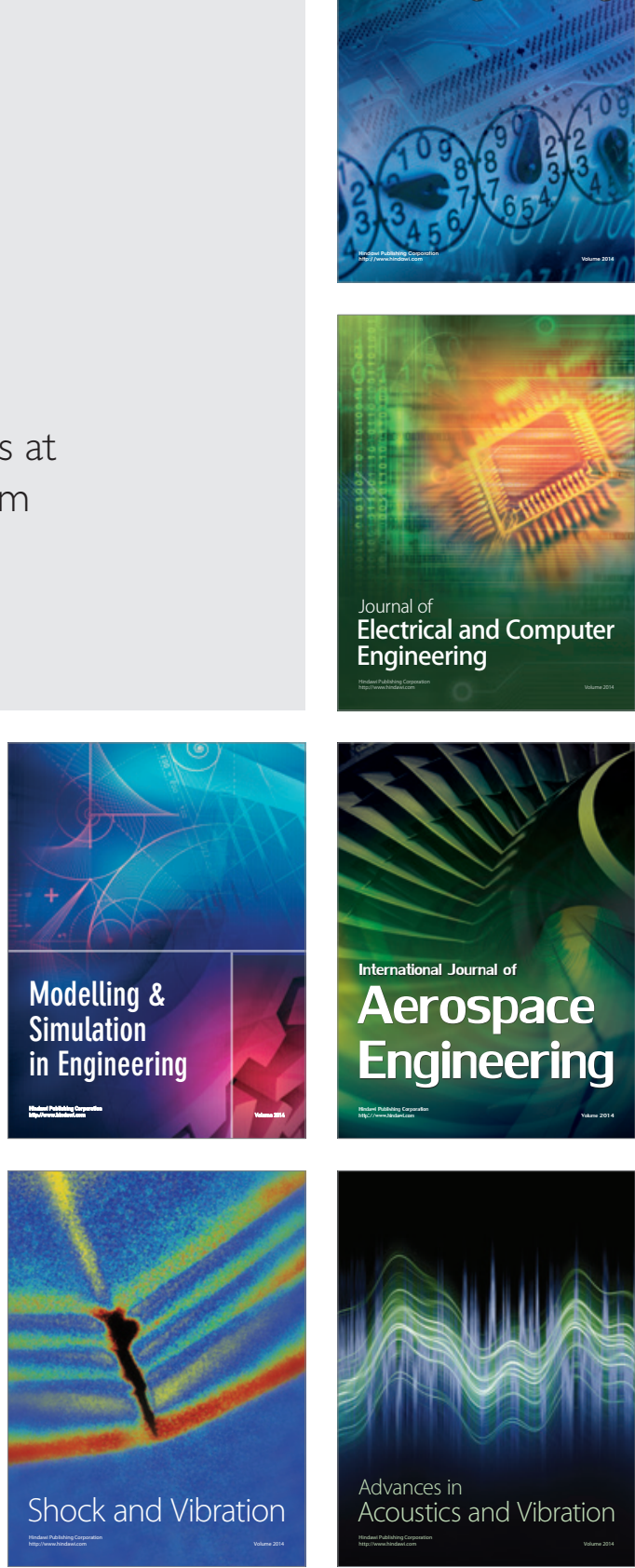